\title{
A MOTIVAÇÃO \\ PARA A PROPOSIÇÃO \\ DE PESQUISAS POR \\ PESQUISADORES DE \\ LINGUÍSTICA: \\ UMA ANÁLISE \\ SOCIORRETÓRICA
}

\section{LA MOTIVACIÓN PARA LAS PROPUESTAS DE INVESTIGACIONES POR INVESTIGADORES DE LINGÜÍSTICA: UN ANÁLISIS SOCIO-RETÓRICO}

THE MOTIVATION FOR PROPOSING RESEARCH BY LINGUISTIC RESEARCHERS: A SOCIORHETORICAL ANALYSIS

Francisco Alves Filho*

Carolina Aurea Cunha Rio Lima**

Universidade Federal do Piauí

\begin{abstract}
RESUMO: O objetivo desta pesquisa é analisar a relação que os passos retóricos 'relatando pesquisa prévia', 'indicando lacuna de pesquisa' e 'indicando problemas do mundo real' mantêm com a proposição de projetos de pesquisa escritos por pesquisadores experientes da área de Linguística. A pesquisa insere-se na sociorretórica e se fundamenta em Swales (1990, 2004), Berkenkotter e Huckin (1995), Connor e Mauranen (1995), Motta-Roth e Hendges (2010), Lim (2012, 2014) e Alves Filho (2018). Foram analisados 12 projetos de pesquisa dentro da Linguística. Os passos encontrados foram quantificados e caracterizados em seus aspectos retóricos, como também foi analisada a relação que essas estratégias possuíam entre si e com a proposição da pesquisa. Os resultados indicam que as pesquisas prévias e as lacunas de pesquisa são pouco utilizadas como argumento para uma nova pesquisa e, em contrapartida, a busca pela resolução de problemas do mundo real é assumida como o principal elemento motivador.

PALAVRAS-CHAVE: Projeto de pesquisa. Lacuna de pesquisa. Pesquisa prévia. Linguística.
\end{abstract}

\footnotetext{
* Professor Associado da Universidade Federaldo Piauí, onde atua na Coordenaça de Letras Vernáculas e no Programa de Pós-Graduação em Letras. É coordenador do Núcleo de Pesquisa Cataphora. Fez doutorado em Linguística pela UNICAMP.E-mail:chicofilhoo@ufpi.edu.br.

** Mestra em Letras (UFPI), graduada em Licenciatura em Letras Português-Francês e Respectivas Literaturas (UFPI), professora substituta no curso de Letras Português-Francês (UFPI) e membro do Núcleo de Pesquisa Cataphora (UfPI). E-mail: carolriolima@gmail.com.
} 
RESUMEN: El objetivo de esta investigación es analizar la relación que mantienen los pasos retóricos 'informando sobre investigaciones previas', 'indicando vacíos de investigación' e 'indicando problemas del mundo real' con la propuesta de proyectos de investigación escritos por investigadores experimentados del área de Lingüística. La investigación se inscribe en la socio-retórica y se fundamenta en Swales (1990, 2004), Berkenkotter y Huckin (1995), Connor y Mauranen (1995), Motta-Roth y Hendges (2010), Lim $(2012,2014)$ y Alves Filho (2018). Se analizaron 12 proyectos de investigación dentro de la lingüística. Los pasos encontrados fueron cuantificados y caracterizados en sus aspectos retóricos, además, se analizó la relación que esas estrategias tenían entre sí y con la propuesta de la investigación. Los resultados indican que las investigaciones previas y los vacíos de investigación son poco utilizadas como argumento para una nueva investigación y, por el contrario, la búsqueda por la resolución de problemas del mundo real es asumida como el principal elemento motivador.

PALABRAS CLAVE: Proyecto de investigación. Vacío de Investigación. Búsqueda previa. Lingüística.

ABSTRACT: The purpose of this research is to analyze the relationship that steps of rhetoric - 'reporting previous research', 'stating research gap' and 'stating real world problems' - hold with the proposing of projects written by expert researchers in Linguistics. The research is inscribed in the Socio-rhetorical and is based on Swales (1990, 2004), Berkenkotter e Huckin (1995), Connor e Mauranen (1995), Motta-Roth e Hendges (2010), Lim (2012, 2014) e Alves Filho (2018). The sample is composed of 12 Linguistic research projects. The steps were quantified and characterized in their rhetorical and lexical aspects, as well as the relationship that these strategies had with each other and with the proposition of the research. The results indicate that previous research and research gaps are little used as an argument for a new research and, in contrast, the search for real world problem solving is assumed as the main motivating element.

KEY-WORDS: Research project. Research gaps. Previous research. Linguistics.

\section{INTRODUÇÃO}

O gênero projeto de pesquisa é bastante presente na vida profissional dos pesquisadores, sejam eles iniciantes ou experientes, tendo em vista ser exigido ao final de cursos de graduação e como pré-requisito em processos seletivos de mestrados e doutorados, além de estar presente em propostas para financiamento de projetos de pesquisadores experientes. Essas diversas situações de realização do projeto de pesquisa evidenciam que os pesquisadores necessitam saber propor uma pesquisa e apresentá-la ao seu leitor, através do projeto de pesquisa. No entanto, as pesquisas que se destinam a desvendar os aspectos retóricos, textuais e contextuais desse gênero são ainda relativamente escassas, apesar de já existirem algumas publicações focadas no estudo da organização retórica desse gênero.

Estes estudos sobre projeto de pesquisa pode ser divididos em três grupos. O primeiro grupo inclui os estudos que possuem uma característica de manual de escrita e que são utilizados como um guia para a elaboração de um projeto (BARROS, 2005; MOTTAROTH; HENDGES, 2010). O segundo grupo congrega pesquisas que descrevem a organização retórica do projeto de pesquisa escrito por pesquisadores experientes como um todo, sem dividi-lo em suas seções (CONNOR; MAURANEN, 1995). Por fim, existem estudos que se detêm na organização retórica de seções específicas de projetos submetidos à seleção de mestrado (RIO LIMA, 2015; SILVA, 2015; MONTEIRO, 2016; ALVES FILHO, 2018) e de projetos de dissertação que foram qualificados no decorrer do mestrado (JUCÁ, 2006).

As pesquisas prévias sobre projeto de pesquisa, de maneira preponderante, foram baseadas em Swales (1990, 2004), pois se apropriam dos seus conceitos de movimentos e passos retóricos, além de buscarem identificar como as seções do projeto se organizam retoricamente. O movimento retórico pode ser compreendido como uma unidade funcional do texto, isto é, que realiza alguma função dentro do texto para que se alcance o propósito comunicativo do gênero (SWALES, 2004). Contudo, o movimento retórico torna-se algo demasiado abstrato e complexo durante a análise, pois sua identificação é feita a partir de fatores extralinguísticos (contextuais), além de poderem existir diferenças entre as análises feitas de um mesmo gênero por diferentes analistas (ALVES FILHO, 2018). 
Os passos retóricos, por outro lado, são uma categoria de análise mais concreta, identificável no texto por meio de marcas linguísticas e que possuem funções retóricas mais específicas que os movimentos. Em outros termos, a identificação dos passos depende, mais concretamente, de uma análise textual, e as marcas linguísticas presentes nos textos permitem que pesquisadores distintos analisem diferentes textos de maneira mais precisa. Os passos se encontram na camada mais textual do gênero, no entanto, não devem ser encarados como forma pela forma. Os passos retóricos se diferenciam dos movimentos porque realizam funções retóricas mais específicas e particulares nos exemplares dos GÊNEROS (ALVES FILHO, 2018). Podemos citar como exemplo o primeiro movimento do Modelo CARS (Create a Research Space) (SWALES, 2004), em que sua função é “estabelecer um território” de pesquisa, mas o estabelecimento desse território só será possível por meio dos passos retóricos "Estabelecer a importância da pesquisa", "Fazer generalizações quanto ao tópico" e "Revisar a literatura". A partir desse exemplo, percebemos que, para estabelecer um território de pesquisa, são necessárias informações mais particulares e que realizem funções mais específicas (passos retóricos), pois são elas que os analistas do gênero percebem no próprio texto.

O que se percebe, por meio dos trabalhos já desenvolvidos com o apoio teórico da sociorretórica, é que existem ainda algumas lacunas. Nenhum dos trabalhos citados anteriormente trabalhou com a análise de passos retóricos específicos dentro de todo o projeto. Isto é, nenhum deles teve como objetivo compreender como as pesquisas prévias, as lacunas de pesquisa e os problemas do mundo real são elaborados para a proposição de uma pesquisa. Outra lacuna pertinente é a não investigação, no Brasil, de projetos de autoria de pesquisadores experientes, tendo em vista que a preocupação tenha se centrado em pesquisadores iniciantes que submeteram seus projetos a uma seleção de mestrado e foram aprovados ou em pesquisadores iniciantes que estão em vias de qualificarem seus projetos de dissertação. Um último aspecto a ser destacado é que as pesquisas prévias focam na descrição retórica das seções do projeto de pesquisa, sem que haja o objetivo de compreender como as estratégias retóricas encontradas funcionam para a proposição da pesquisa, objetivo a ser perseguido neste artigo.

Com base nas observações anteriores, levantamos os seguintes questionamentos: como e a partir do que os pesquisadores experientes da área de Linguística propõem sua pesquisa? Isso se deve a algo que é compartilhado nessa área do conhecimento ou se deve à experiência dos pesquisadores? Diante de tais perguntas, temos como objetivo neste artigo analisar a realização dos passos retóricos 'relatando pesquisa prévia', 'indicando lacuna de pesquisa' e indicando problemas no mundo real' em projetos de pesquisa escritos por pesquisadores especialistas, considerando a relação desses passos com a construção do projeto e do problema de pesquisa na área de Linguística.

Percebemos, consequentemente, pela prática de realização do gênero projeto de pesquisa, que alguns fatores estão envolvidos, quais sejam: a situação comunicativa; a área do conhecimento; e o pesquisador, se iniciante ou experiente. A compreensão de Berkenkotter e Huckin (1995, p. 3) sobre o que são os gêneros dá conta desses três aspectos, pois, para os autores, os gêneros "[...] são estruturas retóricas e dinâmicas que podem ser manipuladas de acordo com as condições de uso e que o conhecimento de gênero é [...] uma forma de cognição situada dentro de atividades disciplinares”.

Os gêneros, nessa perspectiva, são estruturas retóricas dinâmicas porque possuem uma forma identificável tanto para o escritor quanto para o leitor, porém, essa estrutura possui uma funcionalidade e um propósito a ser realizado, além de o conteúdo precisar se adequar à situação comunicativa particular, à epistemologia da área de pesquisa, ao leitor e ao próprio conhecimento que o pesquisador tem sobre o valor de novidade na pesquisa. Tais elementos estão, portanto, relacionados à dinamicidade do gênero, uma vez que o gênero será manipulado de acordo com as convenções sociais de uma comunidade disciplinar, como também buscará atender às necessidades do próprio escritor, o que está intimamente conectado à expertise desse pesquisador.

Dessa forma, a escrita do projeto de pesquisa depende, primeiro, da situação comunicativa em que ele será realizado (conclusão de graduação, seleção de pós-graduação, edital de bolsas de iniciação científica e agências de fomento, dentre outras). Em segundo lugar, essa escrita sofre influência da área do conhecimento em que o projeto está sendo produzido, pois, como a aprendizagem das convenções de gênero acontece no interior de comunidades disciplinares, assim, os escritores irão utilizar estratégias de escrita e irão escolher o conteúdo de acordo com o conhecimento de gênero que adquiriram ao participar de atividades de pesquisa na sua área específica (BERKENKOTTER; HUCKIN, 1995). 
Por fim, a expertise do pesquisador é um terceiro elemento importante ao se considerar a escrita de um gênero. A escrita de projetos de pesquisa feita por pesquisadores experientes no geral evidencia o que é relevante para se propor uma pesquisa em dada cultura disciplinar e a partir de onde a pesquisa parte, pois são esses escritores que possuem uma consciência maior sobre os valores da sua área de pesquisa e mostram na sua escrita o que é importante em relação às pesquisas prévias, às lacunas e aos problemas do mundo real.

A investigação realizada neste trabalho, portanto, mostra-se relevante porque busca evidenciar os eventos deflagradores de uma proposta de pesquisa e a partir de quais conhecimentos ela parte, se teóricos ou de pesquisa ou se, alternativamente, a partir de problemas do mundo real. Essa contribuição busca sanar um problema constante do fazer científico que é a cobrança que se faz a pesquisadores iniciantes e a alunos da graduação que ainda não estão inseridos no mundo da pesquisa de que saibam formular um problema de pesquisa sem que haja um ensino explícito para esse fim.

\section{A PESQUISA CIENTÍFICA E O PROJETO DE PESQUISA}

O ato de pesquisar é recorrente em nosso dia a dia. Quando precisamos saber sobre alguma informação, recorremos às ferramentas de busca na internet e pesquisamos sobre aquilo. No entanto, o ato de pesquisa na academia não pode ser considerado da mesma maneira. A primeira razão para isso é que a pesquisa científica exige do pesquisador a elaboração de uma pergunta que será respondida através de procedimentos metodológicos pré-elaborados (PRODONOV; FREITAS, 2013). Isto é, diferentemente de uma pesquisa na internet ou de uma investigação sobre o funcionamento de um relógio, a pesquisa científica requer planejamento prévio e esse planejamento envolve a delimitação de um tema dentro de uma área do conhecimento, o estabelecimento de questionamentos e de hipóteses, um levantamento bibliográfico capaz de fundamentar o estudo, além da elaboração da metodologia.

O segundo motivo que diferencia a pesquisa científica das pesquisas que empreendemos em nosso dia a dia é a sua relevância. Uma pesquisa científica não é relevante porque é motivada por um gosto ou uma necessidade particular do pesquisador, ou por aquilo que o pesquisador individualmente ainda não sabe, pois esse tipo de pesquisa precisa estar inserido em um corpo de conhecimento. Isso significa dizer que a pesquisa científica, para ser relevante, precisa realizar o movimento de olhar para trás e conhecer as outras pesquisas que já foram feitas, de modo a habilitar o pesquisador a identificar o que ainda precisa ser pesquisado ou o que precisa de aprofundamento.

É exatamente dessa necessidade de se olhar o passado para avançar o conhecimento que tratam Boote e Beile (2005). Os autores defendem que, para uma pesquisa ser, de fato, significativa para sua área do conhecimento, o pesquisador deve ter o conhecimento de pesquisas prévias, saber contextualizá-las dentro da área de pesquisa e estabelecer algum confronto entre elas para mostrar o que ainda precisa ser feito, realizado ou aprendido, seja em termos de teoria, seja em termos de metodologia.

Motta-Roth e Hendges (2010) defendem visão semelhante ao afirmarem que, antes de buscar responder a uma pergunta de pesquisa, o pesquisador deve colocar-se como um pesquisador da literatura de sua própria área, uma vez que somente assim será possível determinar o que é relevante como teoria, como metodologia e como problema de pesquisa. Contudo, ao compreendermos o gênero projeto de pesquisa como uma estrutura retórica e dinâmica e que é manipulada dependendo da situação comunicativa, da comunidade disciplinar e da expertise do pesquisador/escritor (BERKENKOTTER; HUCKIN, 1995), não podemos afirmar que esse caminho de relato de pesquisas para posterior indicação de lacunas seja o que acontece em todas as áreas de pesquisa. Cada área do conhecimento, a partir das suas práticas de pesquisa e de seus objetivos por meio do ato de pesquisar, como também a partir de suas epistemologias, utiliza as estratégias do relato de pesquisa, da indicação de lacunas de pesquisa e da indicação de problemas no mundo real da maneira que mais atende às suas necessidades.

A escrita do projeto de pesquisa está, portanto, inserida em uma comunidade disciplinar ou área do conhecimento específica e as estratégias retóricas utilizadas por pesquisadores experientes evidenciam aquilo que é mais valorizado dentro da área e que irão atender ao caráter persuasivo que o gênero possui. Connor e Mauranen (1999) defendem que os projetos de pesquisa são 
persuasivos porque buscam a todo momento convencer seus avaliadores da importância e relevância da pesquisa que está sendo proposta, ou seja, as estratégias retóricas escolhidas pelos escritores buscam atender a esse propósito do gênero.

A persuasão buscada através do projeto de pesquisa, no entanto, não é explícita. De acordo com Myers (1985 apud TARDY, 2003), o escritor do projeto precisa persuadir seus avaliadores de maneira discreta, sem parecer que quer persuadi-los. Tardy (2003) complementa essa consideração, afirmando que o escritor irá persuadir seu leitor por meio de estratégias que revelam a originalidade da pesquisa, relacionando-a àquilo que é relevante atualmente em uma determinada área.

Os projetos de pesquisa, consequentemente, têm um movimento duplo (TARDY, 2003; BOOTE; BEILE, 2005), já que o escritor precisa ter conhecimento sobre a literatura de sua área, ao mesmo tempo em que necessita evidenciar as insuficiências dentro dela para mostrar a originalidade e relevância de sua pesquisa científica. Alves Filho (2018) mostra que essa complexidade na escrita do projeto de pesquisa é, certamente, algo que dificulta a aprendizagem desse gênero por pesquisadores iniciantes, pois, ao mesmo tempo em que necessitam se colocar como membros daquela área através do domínio do conhecimento já estabelecido, também se veem solicitados a apresentar as falhas que nela existem.

Com base nessa discussão, os passos retóricos 'relatando pesquisa prévia', 'indicando lacuna de pesquisa' e 'indicando problemas do mundo real' estão intimamente relacionados ao propósito comunicativo dos projetos de pesquisa de persuadir oleitor, uma vez que essas três estratégias retóricas estão, a todo momento, relacionando o passado com as necessidades do presente. Em outros termos, a maneira como os pesquisadores experientes da área de Linguística utilizam esses passos retóricos evidencia de que forma a pesquisa científica se torna relevante e facilita aos jovens pesquisadores compreender a complexidade de se pensar em uma proposta de pesquisa relevante e a complexidade de se escrever o projeto de pesquisa.

\section{AS FUNÇÕES E A RELAÇÃO DAS PESQUISAS PRÉVIAS, DAS LACUNAS DE PESQUISA E DOS PROBLEMAS DO MUNDO REAL NA ESCRITA ACADÊMICA}

Lim (2014), em sua pesquisa sobre como doutorandos apresentam suas questões de pesquisa nos capítulos introdutórios de suas teses, mostrou que esses escritores estabelecem uma relação entre as pesquisas prévias e a indicação de lacuna, como também que existe uma relação sequencial entre a indicação de problemas do mundo real e a indicação de lacunas para que se apresente as questões de pesquisa. Em primeiro lugar, podemos destacar que o papel da indicação da lacuna nessas teses é central, uma vez que somente relatar as pesquisas prévias, sem identificar seus problemas, suas insuficiências, não permite ao escritor mostrar ao leitor que seu problema de pesquisa merece investigação. Um dos informantes de Lim (2014) acrescenta que as indicações de lacuna na literatura prévia motivam as questões de pesquisa.

Connor e Mauranen (1999) compartilham dessa visão sobre as funções da lacuna de pesquisa nos projetos de pesquisa propriamente ditos. As pesquisadoras defendem que a lacuna é uma estratégia retórica importante tanto para artigos como para projetos de pesquisa, porque é a existência de um problema, de uma falha no conhecimento prévio que implica na motivação da pesquisa e, consequentemente, na relevância dessa pesquisa, como mostra Lim (2014).

No entanto, quanto à função de uma lacuna de pesquisa e de um problema do mundo real não há consenso. Connor e Mauranen (1999) concebem a lacuna como uma falha tanto na teoria quanto na realidade. Lim (2014), por outro lado, considera que a indicação de problemas do mundo real é uma estratégia separada da lacuna e que serve para fornecer informações prévias sobre algum assunto. Assim, da forma que concebem Connor e Mauranen (1999), tanto a lacuna de pesquisa quanto os problemas do mundo real motivam a pesquisa, enquanto que, em Lim (2014), o problema do mundo real motiva as lacunas de pesquisa que irão implicar em questões de pesquisa e no desenvolvimento de uma pesquisa relevante.

Apesar dessa diferença sobre a relação e a função do problema do mundo real com a lacuna, podemos compreender que os passos retóricos 'indicando problema de pesquisa' e 'indicando problemas do mundo real' partem de conhecimentos diferentes. Lim (2014) 
afirma que a lacuna de pesquisa envolve o relato de uma pesquisa prévia, isto é, para que haja a indicação de uma lacuna, é necessário que o escritor tenha conhecimento da literatura prévia de sua área. Os problemas do mundo real, em contrapartida, são a indicação de problemas descobertos ou observados pelo escritor (LIM, 2014). De acordo com Alves Filho (2018), 'indicando problemas do mundo real' é a apresentação de problemas da vida prática e não de problemas teóricos e metodológicos de uma área do conhecimento.

Dessa forma, a função da indicação dos problemas do mundo real pode variar, sendo ela própria a motivação da pesquisa (CONNOR; MAURANEN, 1999; ALVES FILHO, 2018), ou sendo ela o caminho para a indicação de lacunas de pesquisa que irão motivar diretamente as questões de pesquisa e, consequentemente, uma proposta de pesquisa através do projeto. A função da indicação de lacuna, contudo, é mais estável nas pesquisas prévias que tratam da escrita de teses e projetos por pesquisadores experientes, haja vista que os resultados dessas pesquisas corroboram com o que dizem autores sobre o estabelecimento da relevância da pesquisa através da indicação de lacuna (BOOTE; BEILE, 2005; MOTTA-ROTH; HENDGES, 2010).

Lim (2012), então, apresenta quatro formas de se indicar uma lacuna em introduções de artigos, são elas: 1) "ausência total de pesquisas prévias sobre uma determinada característica"; 2) "destacando pesquisa insuficiente em um aspecto específico"; 3 ) "revelando uma limitação em pesquisa prévia"; ou 4) "contrastando descobertas conflitantes em pesquisas prévias". A primeira realização da indicação de lacuna pressupõe do escritor um conhecimento geral e profundo do que já foi ou não feito em sua área de pesquisa (LIM, 2012), ou seja, o escritor pretende mostrar que fez uma cuidadosa revisão das pesquisas prévias até o presente momento. A afirmação de ausência total de pesquisa pode ser considerada como difícil de ser feita, principalmente nas Humanidades, como na área de Linguística, pois o pesquisador precisaria estar atento a pesquisas do mundo inteiro para poder afirmar categoricamente que há ausência de pesquisa sobre uma característica específica.

A segunda maneira de se indicar uma lacuna, "destacando pesquisa insuficiente em um aspecto específico" (LIM, 2012, p. 235), mostra que poucas pesquisas foram realizadas e busca destacar que a atenção dada a um determinado tópico tem sido inadequada e insuficiente, necessitando, assim, de mais pesquisas para fornecer mais informações. Na terceira realização da indicação de lacuna, "revelando uma limitação em pesquisa prévia”, Lim (2012, p. 238) comenta que os escritores adotam uma postura mais agressiva em suas críticas aos métodos de pesquisa utilizados nas pesquisas prévias, dessa forma, o escritor mostra ao seu leitor que existem lacunas em uma área do conhecimento já bem estabelecida e, em consequência, sua pesquisa permite que o conhecimento nessa mesma área avance, superando as falhas das pesquisas prévias, isto é, o escritor não está seguindo somente uma tradição, ele se insere nela, mas, devido às limitações nas pesquisas prévias, a pesquisa realizada irá avançar no conhecimento e na tradição e isso deve estar explícito ao leitor para indicar a relevância da pesquisa.

A quarta e última realização da lacuna proposta por Lim (2012) tem um caráter menos agressivo que a anterior, pois os escritores irão indicar a lacuna contrastando pesquisas prévias. Explicando de outra maneira, o escritor irá comparar os resultados das pesquisas prévias para mostrar que existe certa inconclusividade nessas descobertas e, implicitamente, indica a necessidade de se ocupar essa lacuna de pesquisa.

É interessante destacar que na escrita da introdução de artigos da área de Administração (LIM, 2012), na escrita dos capítulos introdutórios de teses na área de Linguística Aplicada (LIM, 2014) e na escrita de projetos de pesquisa submetidos à União Europeia (CONNOR; MAURANEN, 1999), a lacuna é um passo recorrente e fundamental não só para mostrar a motivação da pesquisa, mas para conferir-lhe relevância dentro da área de estudo, como também para as agências de fomento. No entanto, na escrita de pesquisadores iniciantes, principalmente no que diz respeito à escrita do projeto de pesquisa, o espaço dedicado à indicação de lacuna é reduzido. Não importa a seção analisada, seja ela a seção de justificativa ou de fundamentação teórica (JUCÁ, 2006; SILVA, 2015; RIO LIMA, 2015; ALVES FILHO, 2018), os jovens pesquisadores tendem a valorizar a capacidade de parafrasear e apresentar os conhecimentos que já estão bem estabelecidos na área, muito mais do que criticá-los.

Os resultados da pesquisa de Alves Filho (2018) mostram, no entanto, que esse conhecimento que é parafraseado e retomado nos projetos de pesquisa dos pesquisadores iniciantes não é aquele das pesquisas prévias. Em sua análise, os passos 'relatando pesquisa prévia' e 'indicando lacuna de pesquisa', os quais são realizados a partir da leitura e da apresentação de pesquisas prévias, tiveram 
uma baixa recorrência quando comparados com a recorrência de passos que requerem o uso de referências bibliográficas teóricas (por exemplo: 'definindo conceitos'). Na conclusão do autor, os jovens pesquisadores têm uma prática de leitura voltada para o domínio dos conceitos e da teoria que fundamentam seu trabalho, sendo escassa a leitura voltada para a identificação de lacunas e problemas de pesquisa, atividade que se realiza por meio das pesquisas científicas efetivas, isto é, que possuem problema de pesquisa, metodologia, resultados e conclusões.

O passo 'relatando pesquisa prévia' tem, portanto, a função de apresentar ao leitor as contribuições das pesquisas prévias, bem como seus aspectos metodológicos, sem enfocar os aspectos conceituais e teóricos (ALVES FILHO, 2018). De acordo com Lim (2014), os estudos prévios permitem que o escritor forneça um conhecimento anterior que sustenta as informações mais específicas sobre seu próprio trabalho. Em outras palavras, a indicação de pesquisas prévias é uma maneira de sumarizar o conhecimento prévio para que o escritor possa, a partir dele, formular suas lacunas e questões de pesquisa.

Com base nos estudos prévios apresentados, não encontramos qualquer discussão acerca da relação entre os passos 'relatando pesquisa prévia' e 'indicando problemas do mundo real'. O que Lim (2014) apresenta é uma relação de alternância entre os dois passos, uma vez que os escritores das teses podem ora apresentar um problema do mundo real para indicar sua lacuna de pesquisa, ora utilizar o relato de pesquisas prévias para esse mesmo fim.

\section{METODOLOGIA}

A amostra desta investigação é composta por doze projetos de pesquisa, escritos por pesquisadores experientes (doutores, professores de programas de pós-graduação e líderes de grupos de pesquisa) da área de Linguística e que foram aprovados em programas de iniciação científica (IC) ou por agências de fomento (AF) entre os anos de 2009 e 2017. Tendo em vista que projetos de pesquisa não são divulgados publicamente, a amostra foi cedida pelos pesquisadores após solicitação via e-mail. Majoritariamente, os projetos são de pesquisadores da região Nordeste do Brasil, mas tivemos acesso a um trabalho da região Sul. Qualquer informação que permitisse a identificação dos autores foi excluída dos dados para preservar o anonimato. Quanto às subáreas a que pertencem, os projetos estão inseridos nas subáreas de gênero de texto/discurso, letramentos, leitura, linguística textual, linguística histórica e gramática.

Por ser nosso objetivo analisar a realização de três passos retóricos específicos, não excluímos nenhum projeto em virtude do formato de sua estruturação ou das seções existentes.

Os projetos de pesquisa foram lidos na íntegra a fim de que fossem localizadas todas as realizações dos passos 'relatando pesquisa prévia', 'indicando lacuna de pesquisa' e 'indicando problemas no mundo real' em todo o projeto. Posteriormente, os passos foram analisados individualmente para que fossem identificados seus aspectos retóricos e lexicais. Cada realização dos passos foi analisada de forma separada, em busca de informações específicas sobre a caracterização dos passos.

A primeira etapa da análise foi quantificar a ocorrência desses passos identificados em todo o corpus, por meio de marcas textuais, como, por exemplo, o uso de verbos de procedimento (analisar, buscar, pretender, investigar etc.) e o uso de verbos de resultados (concluir, demonstrar, mostrar etc.) (MOTTA-ROTH; HENDGES, 2010), que se relacionam ao passo 'relatando pesquisa prévia', além de buscar expressões que gerem oposição (apesar de, todavia, porém etc.) ou palavras de cunho negativo (não, pouco, apenas etc.) que permitiram identificar a indicação de lacunas e de problemas do mundo real (LIM, 2012). Essa análise quantitativa ocorreu em dois momentos. Primeiro, foi observada a presença dos passos nos projetos, isto é, se os passos aparecem ou não nos doze projetos analisados. Essa quantificação foi feita de acordo com a seguinte orientação: se o passo ocorre em um a três projetos (8\% a 25\%), será considerada uma baixa recorrência; na ocorrência do passo em quatro a seis projetos (acima de 25\% até 50\%), tem-se uma média recorrência; e se o passo ocorrer em sete ou mais projetos (acima de 50\%), consideramos uma alta recorrência dentro do corpus. No segundo momento de análise quantitativa, foi contabilizada a quantidade de vezes que um determinado passo retórico apareceu em um único projeto. 
Em seguida, foi feita a caracterização dos passos retóricos. Durante a análise do passo 'relatando pesquisa prévia', foi utilizada como base a definição de Alves Filho (2018), a qual enfatiza que o relato acontece quando o escritor apresenta a metodologia, as descobertas e as conclusões de um estudo anterior já realizado. Consequentemente, esse passo não se relaciona com o relato de conceitos ou teorias utilizadas por pesquisas prévias. Nesse momento, foi feito o levantamento da quantidade de artigos, teses e dissertações utilizados como referência nos projetos, bem como das datas dessas pesquisas prévias.

Para a caracterização do passo 'indicando lacuna de pesquisa', foram utilizadas como referência as descobertas de Lim (2012), nas quais o passo de indicar lacuna pode possuir uma das seguintes características: 1) "ausência total de pesquisas prévias sobre uma determinada característica"; 2) "destacando pesquisa insuficiente em um aspecto específico"; 3) "revelando uma limitação em pesquisa prévia”; ou 4) “contrastando descobertas conflitantes em pesquisas prévias".

$\mathrm{Na}$ caracterização do passo 'indicando problemas do mundo real', foi identificado se esse problema era mediado por leitura de pesquisas prévias ou por apresentação de dados estatísticos públicos ou exames nacionais (como ENEM, SAEB, dentre outros), ou ainda se havia ausência de fontes bibliográficas. É importante saber como o problema do mundo real é percebido pelo escritor, uma vez que a utilização dessas estratégias pode influenciar na construção do projeto de pesquisa e do problema de pesquisa.

A terceira e última etapa da análise dos dados foi a identificação da relação que esses passos mantêm entre si, com o problema de pesquisa e com a construção do projeto de pesquisa. A relação entre os passos foi estabelecida por sua sequencialidade, com base em Lim (2014), ou seja, os passos somente terão relação entre si se ocorrerem um após o outro, pois essa proximidade indica que um passo pode ser a consequência ou o desdobramento do outro. Assim, os passos não estarão relacionados diretamente se estiverem distantes uns dos outros e relacionados a outros tipos de informações.

Na discussão final da análise, os dados encontrados foram relacionados com o discurso de autores sobre a construção do projeto e sobre a relevância de uma pesquisa científica para o avanço do conhecimento dentro de uma área. O intuito foi observar de que maneira os pesquisadores experientes de Linguística propõem sua pesquisa e se essa construção do projeto se distancia ou se aproxima do que fazem os pesquisadores iniciantes.

\section{ANÁLISE E DISCUSSÃO}

\subsection{A FREQUÊNCIA DOS PASSOS RETÓRICOS}

As descobertas feitas após a análise dos projetos de pesquisa mostram que os passos retóricos escolhidos para esta investigação são estratégias retóricas pertinentes à escrita do projeto de pesquisa, haja vista que encontramos suas realizações em todos os projetos, exceto no L12_AF_17, que se mostrou predominantemente teórico. É importante observar que, apesar desses passos terem sido encontrados nos projetos analisados, não significa compreender que um único projeto apresenta obrigatoriamente a realização dos três passos, sendo que em alguns casos o escritor fez uso somente da indicação de lacunas e em outros do relato de pesquisa prévia.

Como vemos na análise quantitativa da realização dos passos e sua presença nos projetos (Tabela 1), o passo indicando problemas do mundo real' ocorreu em oito dos doze projetos, tendo, neste corpus, uma alta recorrência. Por sua vez, o passo 'relatando pesquisa prévia’ ocorreu em seis projetos (média recorrência). Já o passo ‘indicando lacuna de pesquisa’ foi realizado em três projetos (média recorrência), sendo, dentre os três passos analisados, o de menor recorrência. 


\begin{tabular}{|c|c|c|c|}
\hline Projeto & Relatando pesquisa prévia & Indicando lacuna de pesquisa & $\begin{array}{c}\text { Indicando problemas do mundo } \\
\text { real }\end{array}$ \\
\hline L1_IC_17 & - & - & 1 \\
\hline L2_IC_17 & 1 & - & - \\
\hline L3_IC_17 & - & - & 1 \\
\hline L4_IC_13 & 2 & - & - \\
\hline L5_IC_09 & 2 & 1 & 3 \\
\hline L6_IC_16 & 3 & - & 2 \\
\hline L7_IC_14 & - & 1 & 1 \\
\hline L8_IC_16 & - & - & 2 \\
\hline L9_IC_16 & - & - & 1 \\
\hline L10_AF_11 & 1 & - & 1 \\
\hline L11_AF_09 & 1 & 2 & - \\
\hline L12_AF_17 & - & - & - \\
\hline $\begin{array}{c}\text { Total de } \\
\text { realizações em } \\
\text { toda a amostra }\end{array}$ & 10 & 4 & 12 \\
\hline $\begin{array}{l}\text { Total de projetos } \\
\text { em que este passo } \\
\text { ocorre }\end{array}$ & $6 / 12$ & $3 / 12$ & $8 / 12$ \\
\hline
\end{tabular}

Tabela 1: Recorrência dos passos retóricos nos projetos

O contraste entre a recorrência da lacuna de pesquisa e dos problemas do mundo real sugere que, na área de Linguística, os pesquisadores experientes tendem a propor sua pesquisa a partir de dificuldades que podem ser percebidas na realidade e não a partir de insuficiências de pesquisas prévias, sejam elas relacionadas a questões metodológicas ou aos resultados encontrados. Isso sugere uma valorização maior de pesquisas que atuam em problemas que afetam a sociedade como um todo do que da resolução de problemas teóricos e metodológicas do campo da pesquisa acadêmica.

A recorrência do passo 'relatando pesquisa prévia' caminha para reforçar uma postura mais neutra dos pesquisadores em relação aos trabalhos anteriores, pois, apesar de haver o relato de pesquisas prévias, a realização desse passo não ocorre por um posicionamento do escritor acerca dos estudos citados, o que pode indicar também o apoio e a concordância entre o escritor do projeto e o autor citado. Esse passo geralmente é realizado como uma apresentação ou constatação de algo que se sabe através de pesquisas prévias. No trecho (1), o escritor apresenta o que dizem estudos prévios sobre a capacidade de estudantes da graduação de lerem, compreenderem e produzirem os gêneros textuais próprios da academia. 
(1) Embora o sucesso dos estudantes em cursos de nível superior, bem como na carreira acadêmica como tal, dependa amplamente de sua capacidade de ler/compreender e produzir os gêneros textuais requeridos pela academia, estudos (referidos adiante neste projeto) indicam que esses estudantes nem sempre estão preparados para encarar tais desafios. (L10_AF_11)

Outro fator observado é que a média recorrência do passo 'relatando pesquisa prévia' é um indicativo de consciência da importância dessas pesquisas na proposição de um novo estudo. Contudo, olhar somente para a recorrência dos passos nos projetos parece camuflar algumas tendências entre os pesquisadores da área de Linguística. A primeira delas é que os três passos retóricos, em sua maioria, têm somente uma única realização dentro de um único projeto. Isto é, dentro de todo o projeto, o escritor só realizou o passo uma única vez, como é o caso, por exemplo, do L10_AF_11, no qual o relato de pesquisas prévias e a indicação de problemas do mundo real só ocorreram uma única vez.

Com isso, percebemos que, em um quadro geral, o passo 'relatando problemas do mundo real' é o aspecto mais relevante para propor a pesquisa, haja vista o passo ocorrer em oito dos doze projetos analisados, e ter um total de doze realizações nos projetos. Isto é, esse passo é o mais recorrente em comparação com os outros dois analisados. No entanto, assim como observado no passo 'relatando pesquisa prévia' e no passo 'indicando lacuna de pesquisa', a indicação de problemas do mundo real ocorre, em sua maioria, somente uma vez no projeto para evidenciar a motivação da pesquisa. Em relação a esse passo específico, cinco dos oito projetos têm uma única realização.

A indicação de lacuna, por outro lado, mostra-se a menos relevante dentre as estratégias analisadas nos dois aspectos quantitativos, pois foi utilizada em apenas três de doze projetos e sua realização é de uma única vez em dois dos três projetos que a utilizaram. A baixa recorrência desse passo retórico sugere que os pesquisadores experientes de Linguística aqui analisados tendem a evitar conflitos com o que já foi feito em pesquisas prévias.

Em relação ao passo 'relatando pesquisa prévia', apesar de sua média recorrência no corpus, percebemos que, efetivamente, nos projetos, sua realização se divide em três projetos com uma utilização, dois com duas e um com três. Em contraste com a recorrência no total dos projetos, a realização interna desse passo evidencia que, na Linguística, o relato de pesquisas prévias não precisa acontecer diversas vezes ao longo do projeto, sendo sua realização bem pontual.

Por fim, um último dado que pode ser percebido nessa análise quantitativa (Tabela 1) é que os escritores que utilizam o passo 'indicando problemas do mundo real' tendem a não utilizar o passo 'indicando lacuna de pesquisa'. Isso sugere que, como os dois passos funcionam para evidenciar a motivação, o ponto de partida da pesquisa, os pesquisadores escolhem aquele que lhes parece mais relevante. No caso em análise, há uma vasta preferência pela indicação de problemas do mundo real.

\subsection{A CARACTERIZAÇÃO DOS PASSOS RETÓRICOS}

A realização do passo 'relatando pesquisa prévia' nos projetos analisados mostra que os escritores buscam retomar aspectos de estudos anteriores. No entanto, diferente do que foi descrito por Alves Filho (2018), o qual destacava o relato das contribuições por meio dos resultados e descobertas e das propostas metodológicas, nos projetos analisados, as características das pesquisas prévias que são mais destacadas se concentraram na indicação do tema e nos objetivos, havendo também apresentação dos resultados e da conclusão, e, ainda, o surgimento de uma característica nova, que é relatar o posicionamento teórico dos estudos prévios, no exemplo (2). Neste passo não foram encontradas informações metodológicas de pesquisas prévias.

(2) Além deste, outros estudos sobre gêneros numa perspectiva histórica vêm se desenvolvendo no âmbito do Programa de PósGraduação em Linguística (PPGL) desta Universidade. (L4_IC_13)

No geral, seja para apresentar o tema, os objetivos ou qualquer outro elemento de uma pesquisa prévia, os escritores optam predominantemente por agrupar vários estudos anteriores de uma área, utilizando expressões como 'estudos' e 'pesquisas'. Este agrupamento sugere que os escritores não buscam nem individualizar nem mencionar os diversos estudos que existem, mas 
somente apontar, difusamente, que eles existem e que tratam de algum elemento relacionado à pesquisa que está sendo proposta. $\mathrm{O}$ fato de os elementos relatados das pesquisas prévias serem diretamente relacionados ao projeto de pesquisa destaca que essa escolha é feita para valorizar ainda mais a proposta, indicando, implicitamente, que existe uma tradição de pesquisa e que há validade no estudo a ser realizado dentro da área de pesquisa escolhida, como se vê no excerto abaixo.

(3) Contudo estudos realizados em projetos de $\mathrm{AO}$ [objetos de aprendizagem], sobre interações virtuais, gênero textual, internet e ensino, gêneros orais e escritos na escola, o que é virtual, introdução à linguística textual dentre outros mais significativos, e características do mesmo que passam pela acessibilidade, durabilidade e interoperabilidade são de excelente para construção do atual projeto. (L6_IC_16)

Ocorreu, também, mas com menos frequência, a individualização das pesquisas prévias. Em nosso corpus, essa realização ocorreu para indicar o objetivo e o tema. No exemplo (4), o escritor particulariza e detalha o objetivo da pesquisa prévia, relacionando-o com o projeto de pesquisa e aproveita para seguir, explicitamente, uma tradição de pesquisa e dar continuidade a uma pesquisa própria. Já no trecho (5), o escritor aponta a existência de 'estudos' e 'pesquisas teóricas' e cita individualmente o que chama de 'pesquisa teórica', além de apontar que essas pesquisas prévias indicam a relevância desses estudos na área de pesquisa.

(4) Este projeto também pretende dar continuidade aos estudos diacrônicos dos gêneros do discurso, com base na proposta teóricometodológica concebida por mim em minha tese de doutorado ( 2009), quando busquei resgatar o percurso histórico do gênero editorial (carta de redator). (L4_IC_13)

(5) Além de estudos e pesquisas teóricas sobre leitura e escrita propostas por estudiosos, como Kleiman (2013), Marcuschi (2008), Koch (2005) e muitos outros estudos e pesquisas que têm favorecido imensamente o processo de ensino e aprendizagem, tratam-se de informações e descobertas amparadas pelas tecnologias de comunicação e informação que circulam muito rapidamente. (L6_IC_16)

Contudo, a citação explícita de pesquisas prévias na realização do passo 'relatando pesquisas prévias' não é recorrente nos projetos analisados, pois somente duas das dez ocorrências contabilizadas na Tabela 1 utilizam dessa estratégia. Isso sugere, como dito anteriormente, que os escritores preferem reunir as pesquisas prévias dentro de expressões como 'estudos' e 'pesquisas', sem citar quais seriam esses trabalhos prévios. Isto é, há a recorrência do agrupamento dos estudos prévios sob expressões genéricas e o reconhecimento dos escritores de que essas pesquisas existem, mas eles não as citam. No exemplo (5), tem-se a expressão 'muitos outros estudos e pesquisas' e, no trecho (6), a expressão 'pesquisas mostram', porém as referências são imprecisas, haja vista a falta da citação, assim como ocorrem em outras realizações do passo.

(6) Por outro lado, pesquisas mostram que o ensino de Língua Portuguesa nas escolas ainda privilegia os saberes relacionados à tradição da gramática normativa em detrimento de outras habilidades necessárias à plena competência dos saberes relativos aos usos sociais da língua. (L5_IC_09)

A imprecisão nesse passo acontece também no próprio relato das pesquisas prévias, que foca nas generalidades de um conjunto de estudos anteriores sem detalhar o que é particular a eles. Nos excertos (5) e (7), os escritores não citam e não relatam as características das pesquisas prévias, pois rapidamente já passam para justificar uma possível relevância da área e dos próprios estudos que não foram citados.

(7) Além deste, outros estudos sobre gêneros numa perspectiva histórica vêm se desenvolvendo no âmbito do Programa de PósGraduação em Linguística (PPGL) desta Universidade... (L4_IC_13)

Para compreender melhor como o relato das pesquisas prévias funciona, examinamos também quais as principais fontes bibliográficas dos projetos que analisamos (Tabela 2). Para tanto, elas foram divididas em 'referências teóricas' e 'pesquisas prévias'. Percebemos, então, que há uma predominância de citação de livros e capítulos de livros sobre a citação de artigos de pesquisa, teses, dissertações e monografia. Tal dado indica que há, na área de Linguística, uma valorização de expor, no projeto de pesquisa, um 
conhecimento teórico já estabelecido, muito mais do que a discussão sobre metodologias, resultados e conclusões de pesquisas prévias.

É importante ressaltar ainda que, dos seis projetos que apresentaram o passo 'relatando pesquisa prévia' (Tabela 1), quatro estão inclusos na lista de projetos que utilizaram os estudos prévios como fonte bibliográfica (Tabela 2). No entanto, como vimos, apesar de essas referências constarem nas referências bibliográficas utilizadas para a escrita do projeto, elas não são, em sua maioria, citadas para realizar o 'relatando pesquisa prévia'. Uma última informação acerca dessas fontes bibliográficas é que os artigos, as teses e as dissertações utilizados se encaixam, no geral, na observação feita por Alves Filho (2018), de que as pesquisas recentes são das últimas duas décadas, porém, sua utilização na realização do passo 'relatando pesquisa prévia' é baixa.

\begin{tabular}{|c|c|c|c|c|c|c|}
\hline \multirow[b]{2}{*}{ Projetos } & \multicolumn{2}{|c|}{ Referências Teóricas } & \multicolumn{4}{|c|}{ Pesquisas Prévias } \\
\hline & Livro & Capítulo de Livro & $\begin{array}{c}\text { Artigo } \\
\text { de pesquisa }\end{array}$ & Tese & Dissertação & Monografia \\
\hline L1_IC_17 & 7 & 3 & 0 & 0 & 0 & 0 \\
\hline L2_IC_17 & 15 & 3 & 2 & 0 & 0 & 0 \\
\hline L3_IC_17 & 9 & 2 & 0 & 0 & 0 & 0 \\
\hline L4_IC_13 & 5 & 5 & 3 & 2 & 1 & 0 \\
\hline L5_IC_09 & 8 & 1 & 0 & 0 & 0 & 0 \\
\hline L6_IC_16 & 20 & 2 & 1 & 1 & 0 & 0 \\
\hline L7_IC_14 & 19 & 0 & 0 & 1 & 0 & 0 \\
\hline L8_IC_16 & 14 & 0 & 0 & 3 & 0 & 0 \\
\hline L9_IC_16 & 13 & 1 & 0 & 2 & 0 & 0 \\
\hline L10_AF_11 & 21 & 2 & 7 & 1 & 0 & 0 \\
\hline L11_AF_09 & 7 & 14 & 6 & 3 & 1 & 0 \\
\hline L12_AF_17 & 18 & 14 & 4 & 1 & 0 & 0 \\
\hline TOTAL & 156 & 47 & 23 & 14 & 2 & 0 \\
\hline
\end{tabular}

Tabela 2: Fontes bibliográficas dos projetos da área de Linguística 


\begin{tabular}{c|c|c|c|c|c}
\multirow{2}{*}{$\begin{array}{c}\text { Total de referências } \\
\text { nos } 12 \text { projetos }\end{array}$} & \multicolumn{2}{|c|}{ Referências Teóricas } & \multicolumn{3}{|c}{ Pesquisas Prévias } \\
\hline & Livro & Capítulo de Livro & $\begin{array}{c}\text { Artigo } \\
\text { de pesquisa }\end{array}$ & Tese & Dissertação \\
\hline $242(100 \%)$ & $156(64 \%)$ & $47(19 \%)$ & $23(9,5 \%)$ & $14(5,8 \%)$ & $2(0,9 \%)$ \\
\end{tabular}

Tabela 3: Fontes bibliográficas dos projetos da área de Linguística (porcentagem)

Quanto ao passo, 'indicando lacuna de pesquisa', podemos ver (Tabela 1) o mesmo fenômeno que ocorre no passo 'indicando pesquisas prévias', a lacuna só é indicada uma única vez no projeto. O que precisamos observar nessa análise é que, nos projetos de iniciação científica (L5_IC_09, L7_IC_14), a lacuna aparece somente na seção Apresentação e Justificativa, e o restante do projeto é dedicado à apresentação de metodologia, de objetivos, de metas, dentre outras informações que são requeridas. Já no projeto L11_AF_09, o escritor apresenta duas lacunas de pesquisa na seção Problematização e Justificativa. Com base nesse dado, podemos dizer que é possível encontrar algumas lacunas de pesquisa que justifiquem o projeto, e não somente uma. Todavia, no corpus analisado, há a preferência de focar em somente uma única lacuna de pesquisa que possa indicar uma determinada insuficiência da área e que justifique a realização da pesquisa.

Como vemos no exemplo (8), o escritor evidencia que existem esforços para a criação de uma pedagogia de leitura, mas que a pesquisa se insere em uma lacuna dessa pedagogia, a qual não foi capaz ainda de desenvolver conhecimentos acerca da “compreensão da leitura de textos didáticos, por alunos oriundos de contextos sociais menos favorecidos". Ou seja, há uma limitação em relação ao perfil dos sujeitos analisados nas pesquisas prévias (que não seriam alunos oriundos de contextos sociais menos favorecidos) que a pesquisa atual pretende superar.

(8) Mas há alguns esforços bem sucedidos na construção de uma pedagogia da leitura voltada especificamente para a realidade brasileira, como se pode observar nas referências deste projeto. A presente proposta insere-se, todavia, numa lacuna dessa pedagogia, ou seja, o desenvolvimento de um acervo de conhecimento enciclopédico, necessário à compreensão da leitura de textos didáticos, por alunos oriundos de contextos sociais menos favorecidos e, consequentemente, com cultura predominantemente oral. (L5_IC_09)

A limitação metodológica de uma pesquisa prévia (LIM, 2012) é a realização mais recorrente dentre as lacunas encontradas em nossa análise. No caso do trecho (8), há a limitação dos sujeitos. Em outro projeto, o escritor aponta para a inacessibilidade de um determinado local para pesquisas acadêmicas. A indicação de lacuna de pesquisa, porém, ocorre também pelo destaque de algum aspecto específico insuficiente, como é mostrado no excerto (9). Nesse trecho, o escritor destaca que não foram feitas pesquisas que compreendam as mudanças dos gêneros, a partir da visão bakhtiniana.

(9) A compreensão das mudanças por que passam esses gêneros ao serem transmutados (BAKHTIN, 1997) do suporte impresso para o virtual ainda é uma tarefa por executar, apesar dos esforços que têm sido feitos na pesquisa em ciências da linguagem. (L11_AF_09)

A observação dos modos de realização desses passos ainda nos permite destacar que o passo 'indicando lacuna de pesquisa', que normalmente é realizado através da citação de pesquisas prévias (ALVES FILHO, 2018), ocorre sem a citação das mesmas. Em outros termos, as lacunas são indicadas de forma imprecisa e sem qualquer referência explícita a fontes bibliográficas, o que mostra que os trabalhos das últimas duas décadas não são utilizados explicitamente para evidenciar o que já se tem feito na área, tampouco para indicar o que falta nela. Ao relacionarmos as Tabelas 1 e 2, percebemos que um dos três projetos que indicaram lacuna não cita qualquer pesquisa prévia em seu trabalho (L5_IC_09); o outro cita somente a tese do próprio escritor (L7_IC_14); e o último (L11_AF_09) tem em suas referências bibliográficas alguns artigos, teses e dissertações, mas eles não são utilizados para a indicação de lacuna. 
Essa descoberta sugere que os pesquisadores da área de Linguística, ao não citarem pesquisas prévias explicitamente para indicar suas lacunas e nem fazer críticas a elas, buscam evitar conflitos diretos dentro da área. O fato de agruparem estudos prévios em expressões gerais como "esforços", "pesquisas", "produção acadêmica” ou "pesquisas da academia" é outro elemento forte para essa postura mais neutra em relação às pesquisas prévias. Uma outra conclusão a que podemos chegar é que a ausência da utilização das pesquisas prévias no passo 'indicando lacuna de pesquisa' evidencia a necessidade de autoria dessa lacuna, uma vez que o próprio escritor do projeto é quem deve identificar e propor uma lacuna de pesquisa.

Quanto à realização do passo 'indicando problemas do mundo real', um achado importante foi a determinação da utilização ou não de fontes de dados, acadêmicas ou estatísticas, pelos escritores para apontar esses problemas. Em nossa amostra, percebemos que o problema do mundo real pode partir de uma ausência de dados ou de uma ausência de pesquisas prévias, isto é, o escritor constata um problema sem que haja qualquer referência bibliográfica atrelada a ele e também não indica dados estatísticos públicos que possam sustentar essa insuficiência. No exemplo (10), o escritor apresenta a dificuldade que as escolas têm para se adaptar aos alunos com deficiência dentro de um ambiente majoritariamente de alunos sem deficiência. Essa realização sugere que os pesquisadores experientes sustentam o problema, em seu projeto, por meio de um conhecimento próprio daquele ambiente, no entanto, por falta de pistas nos textos analisados, não podemos afirmar categoricamente que essa ausência indica um senso comum entre os pesquisadores da área ou mesmo que essa constatação parte de uma experiência vivenciada pelo próprio escritor do projeto.

(10) Outro aspecto relevante é a dificuldade das escolas em fazer as devidas adaptações, adequações para a efetiva inclusão das alunas e alunos com deficiência na sala comum, além da falta de projeto pedagógico adequado. Para amenizar essas dificuldades, muitas secretarias de educação e escolas chegam a fazer tentativas no intuito de construir condições para melhorar a inserção do aluno nas salas regulares. (L8_IC_16)

A análise das indicações de problemas do mundo real nos mostrou também que os problemas podem ter uma mediação de leitura e é essa mediação que sugere que os problemas do mundo real precisam de alguma validação, seja por meio do conhecimento já explicitado na literatura, seja por meio de dados estatísticos públicos. No trecho (11), por exemplo, o escritor evidencia um grave problema da educação brasileira com base nos resultados dos exames de avaliação do ensino básico brasileiro. Já no excerto (12), o escritor se baseia em considerações feitas por pesquisas prévias que mostram que aquele problema existe.

Esta mediação de leitura e o uso de dados públicos e de pesquisas prévias para a realização do passo indicando problemas do mundo real' sugere que, por ser um projeto de pesquisa científica, isto é, que carece de um planejamento, de uma metodologia e de bases teóricas fundamentais, os escritores se veem na posição de sustentar suas afirmações com base em um conhecimento já estabelecido ou mesmo através de uma interpretação de dados reais. Outro fato interessante sobre tal recorrência é que, neste caso, as pesquisas prévias foram utilizadas para corroborar um problema no mundo real. Em outras palavras, as pesquisas prévias não são alvo de uma crítica, ao contrário, elas servem para ratificar um conhecimento já estabelecido.

(11) O processo ensino/aprendizagem da leitura é hoje um dos principais, senão o principal problema da educação brasileira, como mostram os diversos sistemas de avaliação - estaduais, nacionais e internacionais. (L5_IC_09)

(12)Entretanto, observa-se que essa política de inclusão não tem atingido níveis satisfatórios, conforme apontam algumas pesquisas (BATISTA JR, 2016; SATO, 2013; MENDES, VILARONGA E ZERBATO, 2014), devido à falta de estrutura, recursos e preparo docente. (L9_IC_16)

Após a análise da recorrência e da caracterização dos passos, percebemos que o reconhecimento dos problemas de pesquisa para a escrita de um projeto de pesquisa é muito mais fundamentado na necessidade de resolver alguma dificuldade real, e que o projeto, consequentemente, deve ter um impacto efetivo nas práticas de ensino de leitura ou na inclusão de alunos com deficiência, por exemplo. Isto nos leva a pensar que, na área de Linguística, é mais valorizado empreender pesquisas que são motivadas por esses problemas do mundo real do que críticas a pesquisas prévias. 


\subsection{A RELAÇÃO ENTRE OS PASSOS}

Na análise sobre a relação entre os passos, desconsideramos aqueles projetos que apresentaram a realização de somente um dos três passos analisados e consideramos aqueles que apresentaram, no mínimo, a realização de dois passos retóricos (Tabela 4). Assim, dos cinco projetos que atendem a esse critério, três deles apresentaram alguma relação de sequencialidade entre os passos retóricos.

\begin{tabular}{|c|c|c|c|}
\hline Projeto & Relatando pesquisa prévia & Indicando lacuna de pesquisa & $\begin{array}{c}\text { Indicando problemas do mundo } \\
\text { real }\end{array}$ \\
\hline L5_IC_09 & 2 & 1 & 3 \\
\hline L6_IC_16 & 3 & - & 2 \\
\hline L7_IC_14 & - & 1 & 1 \\
\hline L10_AF_11 & 1 & - & 1 \\
\hline L11_AF_09 & 1 & 2 & - \\
\hline
\end{tabular}

Tabela 4: Projetos que apresentam a presença de dois ou três passos retóricos

As relações encontradas nos projetos L5_IC_09, L6_IC_16 e L10_AF_11 são, majoritariamente, entre os passos 'indicando problemas do mundo real' e 'relatando pesquisa prévia', havendo uma única ocorrência em que 'relatando pesquisa prévia' é seguido do passo 'indicando lacuna de pesquisa' (L5_IC_09). No projeto L5_IC_09 (Quadro 1), a sequência das estratégias 'indicando problemas do mundo real', 'relatando pesquisa prévia' e 'indicando lacuna de pesquisa' mostra que, primeiro, o escritor apresenta um problema do mundo real para, em seguida, mostrar que existem, na academia, trabalho prévios que buscaram sanar esse problema da realidade e que eles foram bem sucedidos. Logo em seguida, apesar dos aspectos positivos dos estudos prévios, o escritor aponta que há uma lacuna na metodologia desses estudos, pois eles não comtemplam um determinado aspecto metodológico. Nesse trecho, portanto, o escritor, para mostrar a relevância e a motivação da pesquisa, parte do mundo real para o mundo da ciência.

\begin{tabular}{c|c|c} 
Indicando problemas do mundo real & Relatando pesquisa prévia & Indicando lacuna de pesquisa \\
\hline $\begin{array}{c}\text { O processo ensino/aprendizagem da } \\
\text { leitura é hoje um dos principais, senão o } \\
\text { principal problema da educação } \\
\text { brasileira, como mostram os diversos } \\
\text { sistemas de avaliação - estaduais, nacionais } \\
\text { e internacionais. }\end{array}$ & $\begin{array}{c}\text { Mas há alguns esforços bem sucedidos na } \\
\text { construção de uma pedagogia da leitura } \\
\text { voltada especificamente para a realidade } \\
\text { brasileira, como se pode observar nas } \\
\text { referências deste projeto. }\end{array}$ & $\begin{array}{c}\text { A presente proposta insere-se, to } \\
\text { numa lacuna dessa pedagogia, ou seja, o } \\
\text { desenvolvimento de um acervo de } \\
\text { conhecimento enciclopédico, necessário à } \\
\text { compreensão da leitura de textos didáticos, } \\
\text { por alunos oriundos de contextos sociais } \\
\text { menos favorecidos e, consequentemente, } \\
\text { com cultura predominantemente oral. }\end{array}$ \\
Quadro 1: Relação entre os passos no projeto L5_IC_09
\end{tabular}

No projeto L6_IC_16, a ordem sequencial dos passos é 'relatando pesquisa prévia' e 'indicando problemas do mundo real', sem o aparecimento da indicação de lacunas (Quadro 2). Nessa relação, o escritor mostra que, na academia, existe a preocupação com um determinado tema e que os resultados dessas pesquisas são positivos. Contudo, o movimento de aplicação das pesquisas científicas no mundo real ainda não ocorreu satisfatoriamente. Diferentemente do que ocorre em L5_IC_09, no qual o escritor evidencia que as pesquisas têm sido aplicadas no mundo real, em L6_IC_16 existe uma relação de causa e efeito entre a existência do problema do mundo real porque as pesquisas não têm sido aplicadas de forma adequada. 


\begin{tabular}{c|c} 
Relatando pesquisa prévia & Indicando problemas do mundo real \\
\hline $\begin{array}{c}\text { Muito já foi publicado e pesquisado sobre este tema, planos e } \\
\text { metas, e os resultados um tanto satisfatório }\end{array}$ & $\begin{array}{c}\text { embora nem sempre colocados em prática, principalmente no } \\
\text { que diz respeito a letramento digital em sala de aula. }\end{array}$ \\
Quadro 2: Relação entre os passos no projeto L6_IC_16
\end{tabular}

Por fim, em L10_AF_11, é retomada a sequência de 'indicando problemas do mundo real' e 'relatando pesquisa prévia' (Quadro 3). O escritor, nesse projeto, utiliza as pesquisas prévias não com seu viés de aplicação e solução dos problemas do mundo real, mas com a função de confirmar o problema do mundo real indicado anteriormente, o que difere das duas realizações anteriormente analisadas.

\begin{tabular}{|c|c|}
\hline Indicando problemas do mundo real & Relatando pesquisa prévia \\
\hline $\begin{array}{l}\text { No dia a dia da atividade acadêmica, percebe-se que os } \\
\text { estudantes do ensino superior, tanto na graduação como na } \\
\text { pós-graduação, encontram expressivas dificuldades para } \\
\text { atender às exigências que o meio lhes apresenta, especialmente } \\
\text { no campo da leitura e da escrita. Embora o sucesso dos estudantes } \\
\text { em cursos de nível superior, bem como na carreira acadêmica } \\
\text { como tal, dependa amplamente de sua capacidade de } \\
\text { ler/compreender e produzir os gêneros textuais requeridos pela } \\
\text { academia, }\end{array}$ & $\begin{array}{l}\text { estudos (referidos adiante neste projeto) indicam que esses } \\
\text { estudantes nem sempre estão preparados para encarar tais } \\
\text { desafios. }\end{array}$ \\
\hline
\end{tabular}

Quadro 3: Relação entre os passos no projeto L10_AF_11

\section{CONSIDERAÇÕES FINAIS}

Diferentemente do que foi indicado em outras pesquisas, as quais consideram que a indicação de lacunas é um passo retórico essencial na proposição e na realização de pesquisas (LIM, 2012, 2014; CONNOR; MAURANEN, 1999; ALVES FILHO, 2018), os achados desta investigação indicam uma baixa ocorrência dessa estratégia e, em seu lugar, uma preferência pela estratégia de indicar problemas do mundo real. Ou seja, através dos projetos, os pesquisadores experientes de Linguística aqui investigados demonstram uma preocupação maior com o impacto que o projeto pode ter para a resolução de problemas, sobretudo na esfera da educação.

No que diz respeito ao relato de pesquisas prévias, foi possível constatar que essa estratégia ocorre irregularmente na amostra e recebe pouca ênfase, tendo em vista ser relatada muito sumariamente. Chama a atenção, nas referências bibliográficas, uma presença menor de artigos de pesquisa quando comparados com a presença de livros e capítulos de livros teóricos. Contudo, os poucos artigos presentes nas referências ainda se mostram pouco utilizados como argumentos para a proposição de uma nova pesquisa, pois, apesar de estarem na lista de referência, esses artigos não são citados no relato de pesquisas prévias, o que sugere a preferência por se posicionar de forma neutra em relação às pesquisas prévias, evitando-se críticas diretas.

Em linhas gerais, os resultados desta investigação se mostram similares àqueles encontrados em projetos de pesquisa de mestrandos (ALVES FILHO, 2018), nos quais as estratégias de relatar pesquisas prévias e indicar lacunas não ocupam um espaço proeminente nas propostas de pesquisa. Com isso, reforça-se a tese de que, na cultura disciplinar de Linguística, a produção de conhecimento novo é mais motivada por questões teóricas (devido à falta do relato de pesquisas prévias) e de intervenção na realidade do que pela crítica às pesquisas anteriores. Também sugere haver um tipo de pesquisa mais conectada com postulados teóricos da área e com demandas da sociedade e menos com as lacunas e imperfeições de pesquisas anteriores. 


\section{REFERÊNCIAS}

ALVES FILHO, F. Como mestrandos agem retoricamente quando precisam justificar suas pesquisas. Revista Brasileira de Linguística Aplicada, v. 18, n. 1, p. 131-158, 2018.

BARROS, J. d'A. Projeto de pesquisa em História: da escolha do tema ao quadro teórico. Petrópolis: Vozes, 2005.

BERKENKOTTER, C.; HUCKIN , T. N. Genre knowledge in disciplinary communication: cognition, culture, power. New Jersey: Lawrence Erlbaum Associates Inc., Publishers, 1995.

BOOTE, D. N.; BEILE, P. Scholars Before Researchers: on the centrality of the dissertation literature review in research preparation. Educational Researcher, v. 34, n. 6, p. 3-15, ago./set. 2005.

CONNOR, U.; MAURANEN, A. Linguistic analysis of grant proposals:european union research grant. English for Specific Purpose, v. 18, n. 1, p. 47-62, 1999.

JUCÁ, D. A organização retórico-argumentativa da seção de justificativa do gênero textual projeto de dissertação. $2006.109 \mathrm{f}$. Dissertação (Mestrado em Linguística) - Programa de Pós-Graduação em Linguística, Universidade Federal do Ceará, Fortaleza, 2006.

LIM, J. M.-H. How do writers establish research niches? A genre-based investigation into management researchers' rhetorical steps and linguistic mechanisms. Journal of English for Academic Purposes, v. 11, p. 229-245, 2012.

LIM, J. M.-H. Formulating research questions in experimental doctoral dissertations on Applied Linguistics. Journalof English for Academic Purposes, v. 35, p. 68-88, 2014.

MONTEIRO, B. N. Organização retórica e estruturação sequencial da seção de metodologia do gênero projeto de pesquisa. 2016. Dissertação (Mestrado em Letras) - Universidade Federal do Piauí, Teresina, 2016.

MOTTA-ROTH, D; HENDGES, G. Produção textual na universidade. São Paulo: Parábola Editorial, 2010.

PRODONOV, C. C.; FREITAS, E. C. de. Metodologia do trabalho científico: métodos e técnicas da pesquisa e do trabalho acadêmico. 2. ed. Novo Hamburgo: Feevale, 2013.

RIO LIMA, C. A. Movimentos retóricos na seção de fundamentação teórica de projetos de pesquisa na subárea de Linguística. Teresina: Pibic, 2015.

SILVA, C. R. B. Movimentos retóricos da seção de justificativa de pré-projetos de pesquisa da subárea de Linguística. Teresina: Pibic, 2015.

SWALES, J. Genre Analysis: English in academic and research settings. Cambridge: Cambridge University Press, 1990. 
SWALES, J. Research Genres: Explorations and applications. Cambridge: Cambridge University Press, 2004.

TARDY, C. A genre system view of the Funding of Academic Research. Written Communication, v. 20, n. 1, p. 7-36, jan. 2003.

(ㄷ) (1) $\circledast$

Recebido em 29/01/2019. Aceito em 29/06/2019. 